\title{
Ego depletion decreases trust in economic decision making
}

\author{
Sarah E. Ainsworth, \\ Florida State University \\ Roy F. Baumeister, \\ Florida State University \\ Kathleen D. Vohs, and \\ University of Minnesota \\ Dan Ariely \\ Duke University
}

\section{Abstract}

Three experiments tested the effects of ego depletion on economic decision making. Participants completed a task either requiring self-control or not. Then participants learned about the trust game, in which senders are given an initial allocation of $\$ 10$ to split between themselves and another person, the receiver. The receiver receives triple the amount given and can send any, all, or none of the tripled money back to the sender. Participants were assigned the role of the sender and decided how to split the initial allocation. Giving less money, and therefore not trusting the receiver, is the safe, less risky response. Participants who had exerted self-control and were depleted gave the receiver less money than those in the non-depletion condition (Experiment 1). This effect was replicated and moderated in two additional experiments. Depletion again led to lower amounts given (less trust), but primarily among participants who were told they would never meet the receiver (Experiment 2) or who were given no information about how similar they were to the receiver (Experiment 3). Amounts given did not differ for depleted and non-depleted participants who either expected to meet the receiver (Experiment 2) or were led to believe that they were very similar to the receiver (Experiment 3 ). Decreased trust among depleted participants was strongest among neurotics. These results imply that self-control facilitates behavioral trust, especially when no other cues signal decreased social risk in trusting, such as if an actual or possible relationship with the receiver were suggested.

\section{Keywords}

Self-control; ego depletion; trust; cooperation

\footnotetext{
(C) 2014 Elsevier Inc. All rights reserved.
}

Publisher's Disclaimer: This is a PDF file of an unedited manuscript that has been accepted for publication. As a service to our customers we are providing this early version of the manuscript. The manuscript will undergo copyediting, typesetting, and review of the resulting proof before it is published in its final citable form. Please note that during the production process errors may be discovered which could affect the content, and all legal disclaimers that apply to the journal pertain. 
Protecting oneself against risk and harm is surely one of the most basic and adaptive tendencies in nature. Making oneself vulnerable to being harmed by someone else violates that tendency, and so it seems likely that most creatures would be reluctant to do so. Sometimes, however, there are large benefits to be gained by making oneself thus vulnerable, and people manage to trust others: that is, they place themselves in another's power, buoyed by confidence that the other person will use that power to benefit rather than harm them. Trust is perhaps especially difficult, though also perhaps especially necessary, when the other person has a self-interested or other reason to inflict harm.

The present research investigated factors that enable people to trust each other or inhibit them from doing so. We reasoned that the need to cooperate may have created some natural tendencies to trust, most obviously in a human infant's need to trust its caregivers. We also assumed that trusting strangers is considerably more risky and therefore less common (e.g., Fetchenhauer \& Dunning, 2009), so that people would have to use self-regulation to override skeptical or skittish impulses in order to trust. One hypothesis was that trusting strangers would diminish when self-regulation was hampered by depletion of resources. Another hypothesis was that the impact of self-regulation and depletion on trust would be reduced if cues would align with natural tendencies toward trust, such as if some actual or possible relationship with the trustee were suggested.

\section{What is Trust?}

Trust can be considered a combination of cognition and emotion: It is a feeling of security based on a belief or expectation that another person will provide benefit rather than harm (Mayer, Davis, \& Schoorman, 1995; Rousseau, Sitkin, Burt, \& Camerer, 1998). It may be also considered a behavior: specifically, a willingness to put oneself in a situation of dependency on another person (who therefore has the power to confer benefits or costs). The present investigation focused on the latter (behavioral) form of trust.

Early conceptualizations defined trust in terms of dispositional characteristics of a single actor (Rotter, 1971). More recent models conceptualize trust as an interpersonal phenomenon that exists between two people in a relationship (Holmes \& Rempel, 1989; Rempel, Holmes, \& Zanna, 1985; for a review see Simpson, 2007). Dyadic models suggest that trust depends not only on characteristics of the actor (the truster) and the potential recipient (the trustee) but also on characteristics of the relationship between them. Thus, the same two people may trust each other to varying degrees as a function of the relationship between them.

The interpersonal structure of a situation requiring trust was elucidated by Righetti and Finkenauer (2011). Those authors articulated three relevant dimensions. The first was interdependence (see Kelley \& Thibaut, 1978). That is, trust is needed when the outcome of the truster depends on the behavior of the trustee. The second dimension of trust is risk. Not all instances of interdependence create equal risk. Interdependence only creates risk when the desired outcomes of two people conflict, such as when a positive outcome for one person necessarily leads to a worse outcome for another person (see also Balliet \& Van Lange, 2013). The third dimension of trust is that the truster must be free to decide whether to trust 
or not. If a person is coerced or forced to rely on another person, then that is not evidence of trust. Based on this analysis, we conceptualized trust as a dyadic process in which the truster freely chooses to accept risk by depending on another person to achieve a desirable outcome.

Operationally, behavioral economists have developed a measure of (behavioral) trust, called the trust game (Berg, Dickhaut, \& McCabe, 1995). One person is given a sum of money and offered the options of simply keeping all of it or giving any or all of it to another person.

The amount the person gives is tripled by the experimenter, and the recipient is then allowed to return any part (or all or none) of the tripled amount to the original person. Thus, trust produces benefits, insofar as the total amount of money is increased. The trust game invokes all three of the Righetti and Finkenauer (2011) dimensions. Interdependence exists insofar as the maximum mutual outcome requires both players to cooperate. Risk is substantial, because either player can keep all the money so the other gets nothing. Choice to trust is free, as that is the essence of the game. Dunning, Fetchenhauer, and Schloesser (2012) confirmed that people construe the trust game as involving trust and faith in others.

\section{Why Trust?}

As already stated, behavioral trust puts oneself at risk of being harmed or exploited by others, and in that sense it may seem irrational or self-defeating. Trust occurs, however, because it also facilitates benefits (Campbell, Simpson, Boldry, \& Rubin, 2010; de Jong \& Elfring, 2010; Knack \& Keefer, 1997; McKnight, Cummings, \& Chervany, 1998; Zaheer, McEvily, \& Perrone, 1998). Most obviously, young mammals require care and protection and must trust others to help them survive. Whether others will reward that trust by providing such care, including at cost to self, may violate self-interest. Insofar as the brain's purpose is to facilitate the survival of the body that houses it, self-interest would dictate taking advantage of trusters rather than benefiting them. However, the shift in evolutionary theory from bodily selfishness to genetic selfishness (see Dawkins, 1976; Hamilton, 1964) proposed that nature has found one solution to this problem. Animals may be innately predisposed to cooperate with and help others who share their genes. Trust should therefore occur between kin. Having a relationship would thus facilitate trust. To be sure, animals cannot conduct genetic tests on each other, but various cues indicate that a relationship exists and could thereby foster trust.

Cooperating with strangers, especially when trust is required, is considerably more difficult than trusting kin. Yet some theorists have argued that it is central to human life and possibly a key to understanding how humans differ from other animals. For example, Fukuyama (2011) has analyzed the transition from kinship-based small groups into large societies as a vital (yet always incomplete) step toward creating national societies, with all the advantages these confer (e.g., progress, military defense, social safety nets). Perhaps even more important, economic trade and other transactions require trust (Fukuyama, 1996; Rose, 2011). Even just purchasing a hamburger involves trust that the meat is actually beef, that it has been prepared well and kept safe from infection, that the amount is correct, that the change one receives is not counterfeit, and so forth. The seller likewise trusts that the diner can and will pay for the hamburger after it has been eaten. Given the enormous power of 
economic trade to enhance collective welfare, the benefits of the requisite trust to facilitate trade can hardly be overstated. Yet of course the conflict of interest that makes such trust risky is often evident in economic behavior, insofar as vendors are tempted to cheat or mislead customers.

The behavioral trust game developed by Berg et al. (1995) captures these features as well as the dimensions of trust listed by Righetti and Finkenauer (2011). Much like how trust facilitates trade, which in turn increases total wealth, the trust game triples the amount of money that the first player chooses to invest. Yet the conflict of interest is an important feature of the trust game. In particular, the recipient can maximize his or her own gain by keeping all the money rather than returning any share to the sender.

\section{Trust and Relationships}

As we have said, nature may have prepared people (and other animals) to trust genetic kin. Being related is thus an important foundation of trust. In order to facilitate trust with nonkin, humans may create other kinds of relationships that facilitate trust and cooperation. The trust game is again relevant, insofar as one is dealing with a stranger but may have a sense of initiating a relationship by trusting. Klapwijk and van Lange (2009) showed that initial generosity is a powerful yet underappreciated factor for building and maintaining trust. By giving most or all of the money to the other person in the trust game, the initial player is not only expressing trust but also being generous in a way that has often worked to build trust. Delton, Krasnow, Cosmides and Tooby (2011) showed that people often treat strangers met for the first time as if they were seeking to establish a cooperative relationship. That is, people may have evolved to treat strangers as potential relationship partners. Insofar as this prosocial tendency is largely unprecedented in nature and fraught with vulnerability to exploitation, it would be quite tentative and easily abandoned. Hence it is important to consider what might facilitate versus inhibit the willingness to trust strangers.

The present investigation used two procedures to activate cues suggestive of relatedness. One was bogus feedback about biological resemblance. Shared genes produce similar physical traits, so resemblance is a potent cue. Even beyond biological resemblance, similarity is a powerful impetus to interpersonal attraction and relationship formation (Brewer, 1979; Byrne, 1961; Newcomb, 1956; Tajfel \& Turner, 1986). Attitude similarity can even serve as a heuristic kinship cue (Park \& Schaller, 2005). Our hypothesis was that trust should arise relatively easily and naturally between people who believe themselves to be quite similar to each other.

The other procedure was the expectation of an imminent face-to-face meeting. In most studies that use the trust game, the players are told they will never meet each other nor learn each other's identities (Berg, Dickhaut, \& McCabe, 1995; Fetchenhauer \& Dunning, 2009; Fetchenhauer \& Dunning, 2012). The game is thus a one-shot anonymous interaction, which makes trust relatively difficult because the other person may be highly tempted to exploit the situation (and thereby exploit the truster) for individual advantage. One experiment using the trust game asked participants to indicate whether they believe the trustee would return any of the money (Fetchenhauer \& Dunning, 2009). Consistent with the idea that people may 
fear exploitation in the trust game, $45 \%$ of the participants said they believed their partner would keep all the money for him or herself. In contrast, expecting to meet the other person creates a chance for starting a relationship.

Although Delton et al. (2011) were not explicitly writing about trust, their analysis is helpful. They contrasted the errors of mistaking a one-shot interaction for a potential new relationship, which leaves one open to be exploited, and mistaking a potential new relationship for a one-shot interaction, which tempts one to exploit the other. The failure to develop cooperative relationships would be much more costly in the long run. Hence humans may be inclined to try cooperation, albeit cautiously and tentatively at first.

\section{Self-Control, Depletion, and Trust}

In a compelling series of studies, Righetti and Finkenauer (2011) showed that self-control invites trust. That is, people were more willing to trust someone with good than with poor self-control. The reason, presumably, is that trusters anticipate that trustees with good selfcontrol will be able to resist the temptation to exploit for short-term advantage.

We extended Righetti's and Finkenauer's analysis to the truster. Just as (and because) trustees may be tempted to exploit, trusters may be tempted to distrust them. Self-control typically operates to advance long-term goals when these conflict with short-term ones (e.g., Baumeister, Heatherton, \& Tice, 1994). The long-term goal of forming cooperative relationships with others requires some degree of trust, but when the chances of being exploited loom large, people may be inclined to withhold trust. In that case, self-control can override the skepticism and enable the person to take the risky step of making oneself vulnerable to the other.

Self-control is however not a constant character trait but rather a fluctuating capability. Much work has shown that prior exertion of self-control can deplete resources, leading to a temporary impairment of further self-regulatory attempts (e.g., Baumeister, Bratslavsky, Muraven, \& Tice, 1998; Vohs, Baumeister, \& Ciarocco, 2005; for meta-analysis, see Hagger, Stiff, Wood, \& Chatzisarantis, 2010). The state of impaired capacity for selfregulation caused by having expended resources has been dubbed ego depletion. Insofar as trust depends on self-control, people should become less trusting when in the ego depleted state.

We have proposed that trust depends on self-control, especially when the situation is relatively risky, such as trusting a complete stranger with no basis for assuming there is a relationship. Insofar as ego depletion reduces the capacity for self-control, it should hamper trust. Hence we hypothesized that people would exhibit lower levels of behavioral trust when depleted.

Thus, our primary hypothesis was that ego depletion would reduce behavioral trust. Additional hypotheses invoked the assumptions that reluctance to trust varies as a function of relationship status, such that people trust more easily and readily when the trustee may have an actual or potential relationship to the truster than when no relationship is apparent. We suggested that cues indicating biological similarity and/or the anticipation of a face-to- 
face meeting would evoke the possibility of a relationship and therefore facilitate trust. Our secondary hypothesis therefore proposed that the detrimental effect of ego depletion on behavioral trust would be mitigated by those cues, because a relationship-oriented mindset trusts more automatically then a mindset oriented toward stranger interactions.

\section{Neuroticism}

Neuroticism is one of the Big Five Personality traits, associated with having many complaints about problems, bad feelings, and ailments. Evans and Revelle (2008) found that neuroticism correlated substantially $(r=-.57)$ with a survey measure of trust. Evans and Revelle proposed that neuroticism may inhibit trust because neurotics are highly attuned to negative outcomes. As evidence, neurotics tolerate more risk to avoid losses, but tolerate less risk to achieve benefits (Levin, Gaeth, Schreiber, \& Lauriola, 2002; Lauriola \& Levin, 2001). In the trust game, trusting is done to achieve benefits, and so neurotics would presumably be less willing to trust than other people.

Thus, neurotics may be less trusting than other people because they are less willing to accept vulnerability to achieve the potential benefits associated with trust. To overcome their aversion to negative outcomes when deciding about whether to trust others, neurotics may be especially dependent on self-control. We therefore predicted that depletion-related decreases in trust would be larger among neurotics than non-neurotics.

\section{Experiment 1}

Experiment 1 was designed to test the basic prediction that self-regulatory depletion would lead to decreased behavioral trust. Depletion was manipulated by requiring some participants to regulate their attention while watching a video clip. That is, they were instructed to avoid looking at superfluous words that appeared on the screen, whereas participants in the non-depletion condition were not given any instructions about how to direct their attention. All participants then completed the trust game with an ostensible other person. We expected participants who were asked to control their attention during the video clip to make lower offer amounts to the other person than participants who had not been asked to regulate their attention.

\section{Method}

Participants-Sixty-one participants completed the experiment for partial course credit for their Introduction to Psychology courses. Because Introduction to Psychology satisfies general education requirements, students from any major are allowed to enroll in the course. Participants received $\$ 5$ after completing the trust game, but they were unaware at the time they signed up for the experiment that they would receive this additional payment. Eight participants who failed instruction checks for the trust game were excluded, leaving a total of 53 participants (31 women).

Procedure-Participants arrived to the lab individually and were randomly assigned to the depletion or non-depletion condition. The depletion manipulation involved watching a silent video of a woman being interviewed by an off-camera interviewer (adapted from Gilbert, 
Krull, \& Pelham, 1988), a task ostensibly designed to measure non-verbal impressions. Throughout the seven-minute interview, neutral words (e.g., hat) appeared intermittently at the bottom right corner of the screen. Participants in the depletion condition were instructed that it was crucial that they control their attention by ignoring the words and immediately refocusing their attention on the woman if they looked at the words. Participants in the nondepletion condition were not given specific instructions about the words. This depletion task has been used successfully in past research to deplete self-regulatory resources (e.g., DeWall, Baumeister, Mead, \& Vohs, 2011; Masicampo \& Baumeister, 2008). Following the depletion manipulation, participants completed the Brief Mood Introspection Scale (BMIS; Mayer \& Gaschke, 1988) to provide a measure of mood and arousal.

Next, participants completed the trust game with an ostensible other person (Berg, Dickhaut, $\&$ McCabe, 1995). The trust game has been used primarily in behavioral economics experiments to measure people's willingness to trust others in economic exchanges. Instructions for the game were presented on the computer. Participants were told that they would complete an economic decision making task for real money with another participant who was subject to the same earning possibilities. The identity of the participant and the other person would remain confidential. Next, participants were told that they were randomly assigned to the role of Player A and the other participant to the role of Player B.

The game rules then stated that the participant (Player A) would receive 10 experiment dollars, which would be converted to payment for real money at the end of the experiment. The participant could decide whether to send some, none, or all of the experiment dollars to the other player. Any money sent by the participant to the other player would be tripled. Participants were given the example that if they choose to send nothing, the other player would receive nothing. If they send 3 experiment dollars, the other player would receive 9 experiment dollars. If they send 10 experiment dollars, the other player would receive 30 experiment dollars. Participants were then informed that the other player must decide whether to send some, none, or all of the money received back to the participant. An example stated that if the participant sent 3 experiment dollars, the other player would receive 9 experiment dollars and could return any amount between 0 and 9 experiment dollars.

To clarify earning potentials, participants were informed that their payment would be the sum of the amount they kept for themselves out of the original 10 experiment dollars and the amount that the ostensible other player sent back to them. Thus, participants were told that their payment at the end of the experiment could be more than, less than, or equal to $\$ 10$. In spite of these stated earning potentials, it was not possible to calculate payment this way because there was no other player in the experiment. Instead, we paid all participants $\$ 5$ in addition to the partial course credit they received for participating.

Participants then completed the Big Five Aspects Neuroticism Scale ( $a=.87$; DeYoung, Quilty, \& Peterson, 2007). The Big Five Aspects Neuroticism Scale is composed of two facets, labeled Volatility and Withdrawal. The Volatility facet $(a=.88)$ measures irritability, anger, emotional lability, and difficulty controlling emotional impulses, and the Withdrawal facet $(a=.71)$ measures the propensity to experience negative affect. Participants reported 
how characteristic each statement is of them on a 5-point Likert-type scale $(1=$ not at all characteristic of me; $5=$ extremely characteristic of me).

Participants were then asked four questions to check whether they fully understood the instructions of the trust game. The questions asked participants to indicate how many experiment dollars they received at the beginning of the game (10 experiment dollars), whether they had been assigned to be Player A or Player B (Player A), what was the possible amount of experiment dollars they could send to the other person (any amount from 0 to 10), and how many experiment dollars the other person could send back to them (any amount from 0 to three times the amount sent by the participant).

Results

Trust Game-The major dependent variable in this experiment was the participant's offer in the trust game. We predicted that participants in the depletion condition would offer less money to the other person than participants in the non-depletion condition. To test this hypothesis, we submitted participants' offer amounts to an independent samples $t$-test. This analysis yielded a marginal effect of depletion condition on trust game offer amounts, $t(51)$ $=1.98, p=.05, d=.54$. Consistent with the hypothesis, participants in the depletion condition entrusted less money to the ostensible other person $(M=\$ 4.31, S D=\$ 2.35)$ than participants in the non-depletion condition $(M=\$ 5.64, S D=\$ 2.53)$.

Moderation Analyses-Multiple regression was used to test whether neuroticism scores on the Big Five Aspects Scale moderated the effect of depletion condition on trust game offers. Depletion condition, neuroticism scores, and their centered interaction were entered as predictors of trust game offers. There was no main effect of neuroticism, $\beta=0.08, p=$. $57, r_{\text {partial }}=.08$, but there was a main effect of depletion condition, $\beta=-0.26, p=.05$, $r_{\text {partial }}=.-27$. This main effect was qualified by a significant interaction between depletion condition and neuroticism, $\beta=-.30, p=.03, r_{\text {partial }}=-.31$. We tested the effect of depletion condition at high (1 SD above the mean) and low (1 SD below the mean) levels of neuroticism. Simple slope analyses indicated that at high levels of neuroticism, depleted participants entrusted less money than non-depleted ones, $\beta=-0.56, p=.004, r_{\text {partial }}=-.40$, but depletion made no difference at low levels of neuroticism, $\beta=0.05, p=.81, r_{\text {partial }}=.04$.

Because the Neuroticism subscale of the Big Five Aspects scale is composed of the Volatility and Withdrawal facets, additional regression analyses tested for moderation by each subscale. In the first regression, depletion condition, Volatility scores, and their centered interaction were entered to predict offer amounts in the trust game. The main effect of depletion condition was significant, $\beta=-0.26, p=.047, r_{\text {partial }}=-.28$, and the interaction between depletion condition and Volatility was significant, $\beta=-0.34, p=.01, r_{\text {partial }}=-.36$. Simple slope analyses (at 1 SD above and below the mean of Volatility) indicated an effect of depletion condition on offer amounts at high levels of Volatility, $\beta=-0.61, p=.002$, $r_{\text {partial }}=-.43$, but not at low levels of Volatility, $\beta=0.09, p=.64, r_{\text {partial }}=.07$. In the second regression, depletion condition, Withdrawal scores, and their centered interaction were entered to predict offer amounts in the trust game. The interaction of depletion condition and Withdrawal failed to reached significance, $\beta=-.17, p=.23, r_{\text {partial }}=-.17$, indicating that the 
moderation analyses reported for neuroticism above were driven primarily by the Volatility subscale of the Big Five Aspects scale.

Mood-We also ran additional analyses to address whether differences in mood valence or arousal due to the depletion condition can account for differences in trust game offer amounts. Two independent samples $t$-tests were conducted with depletion condition predicting each subscale of the Brief Mood Introspection Scale (BMIS; Mayer \& Gaschke, 1988). There were no differences between the depletion and non-depletion conditions in reported mood valence, $p=.78$, or mood arousal, $p=.51$. As an additional check, we reran the primary trust game analyses controlling for mood valence and arousal. A one-way ANOVA with depletion condition as a predictor of trust game offers, controlling for mood valence and arousal, remained marginally significant, $F(1,49)=3.80, p=.06, \eta^{2}=.07$. Additionally, the interactions between depletion condition and neuroticism, $\beta=-0.32, p=$. $02, r_{\text {partial }}=-.34$, and between depletion condition and Volatility, $\beta=-0.35, p=.009, r_{\text {partial }}$ $=-.37$, remained significant when controlling for mood valence and arousal. Thus, mood did not mediate the effects of depletion on trust.

\section{Discussion}

Experiment 1 provided initial evidence that ego depletion reduces behavioral trust. Participants who controlled their attention during a video clip subsequently sent less money to the other person in the trust game than participants who did not control their attention.

The decrease in trust among depleted participants was moderated by neuroticism. Whereas depletion led to decreased trust among people who scored high on neuroticism, there were no differences in trust between depleted and non-depleted people who scored low on neuroticism. This finding suggests that neurotic people may depend more on self-control to promote trust than non-neurotic people.

Additional findings suggest that the moderating effect of neuroticism was driven by one particular facet of the Big Five Aspects neuroticism scale, the Volatility facet (Cunningham, Arbuckle, Jahn, Mowrer, \& Abduljalil, 2010; Van Doorn \& Lang, 2010). The Volatility facet of the Big Five Aspects Neuroticism scale is associated with paying attention to negative information, making negative attributions, and experiencing agitation or anger. We predicted that neurotics may depend more than other people on self-control to trust others because trust requires becoming vulnerable to exploitation. People who score high on Volatility may be particularly attuned to the potential negative outcomes associated with trust and may therefore depend on self-control to override their fear of exploitation.

\section{Experiment 2}

Experiment 2 was designed to replicate and extend the results of Experiment 1 in two ways. First, Experiment 2 employed a different depletion manipulation to increase generalizability. This depletion manipulation consisted of a writing task in which participants were asked to omit either two high-frequency letters (depletion condition) or two low-frequency letters (non-depletion condition) from their writing. Writing without high-frequency letters was 
expected to be more depleting than writing without low-frequency letters because the former task demands more control of attention and because more responses must be overridden.

Second, Experiment 2 was designed to test for a boundary condition for the reduction of trust during depletion. Specifically, we predicted that self-control may be particularly necessary for facilitating trust when the situation is perceived as relatively risky (Fetchenhauer \& Dunning, 2009), such as when trusting a complete stranger with no prospect of forming a relationship. To test this prediction, Experiment 2 manipulated whether participants expected a future meeting with the other person. When the participants expect a future meeting with the other person, the decision to trust may be perceived as less risky because the expectation of meeting evokes the possibility of developing a relationship of some kind with that person. We therefore predicted that self-regulatory depletion would lead to decreased trust primarily among participants who did not expect to meet the other person.

\section{Method}

Participants-Seventy-nine participants completed the experiment for partial course credit for their Introduction to Psychology courses. Participants received $\$ 5$ after completing the trust game, but they were unaware at the time they signed up for the experiment that they would receive this additional payment. Seven participants who failed to answer instruction check questions about the trust game correctly were excluded, leaving a total of 72 participants (51 women).

Procedure-Participants arrived individually to the lab and were randomly assigned to the depletion or non-depletion condition. The depletion manipulation in this experiment was a writing exercise in which participants were given instructions to alter their writing in ways that would either consume or preserve self-regulatory resources. All participants had five minutes to respond to each of three prompts that asked general questions, such as "Describe what you do on a typical weekday. Begin with the moment you wake up and end with the moment you go to sleep." Participants in the depletion condition were told: "Very important! Please do not use the letters 'A' or ' $\mathrm{N}$ ' anywhere in your story." Participants in the non-depletion condition were given the same instructions but were told not to use the letters ' $\mathrm{X}$ ' or ' $\mathrm{Z}$ ' instead of the letters ' $\mathrm{A}$ ' and ' $\mathrm{N}$ '. Writing without the high frequency letters ' $A$ ' and ' $N$ ' requires more self-regulation than writing without the low frequency letters ' $\mathrm{X}$ ' and ' $\mathrm{Z}$ '. This depletion manipulation has been used successfully in past research to deplete self-regulatory resources (e.g., Mead, Baumeister, Gino, Schweitzer, \& Ariely, 2009; Pocheptsova, Amir, Dhar, \& Baumeister, 2009; Schmeichel, 2007). Following the writing task, participants were asked to report on a 7-point Likert-type scale how much the task required them to override their typical way of writing, to exert effort, and to exert control $(1=$ not at all, $7=$ very much $)$. Participants' responses to these questions were averaged to provide a self-report check of depletion $(a=.96)$. Participants then completed the Brief Mood Introspection Scale (BMIS; Mayer \& Gaschke, 1988) to provide a measure of mood and arousal. 
Next, participants completed the trust game with an ostensible other person. The instructions received were identical to the instructions used in Experiment 1 with one exception. Participants were randomly assigned to a future meeting or no future meeting condition. Participants in the future meeting condition were told that they would be introduced to the other person after the trust game, and participants in the no future meeting condition were told that they would not be introduced to the other person at any time. All participants were told that the experimenter would have not have access to their decisions in the game.

After the trust game, participants again completed the Big Five Aspects Neuroticism Scale ( $a=.88$; DeYoung, Quilty, \& Peterson, 2007; Volatility subscale $a=.86$; Withdrawal subscale $a=.74$ ) and the trust game instruction check questions reported in the method for Experiment 1.

\section{Results}

Manipulation check-A $2 \times 2$ ANOVA was run to test for differences in perceived effort on the writing task by depletion condition, meeting condition, and their interaction. There was a main effect of depletion condition, $F(1,68)=75.62, p<.001, \eta^{2}=.53$. Depleted participants $(M=6.47, S D=0.75)$ found the writing task much more demanding than nondepleted participants $(M=3.41, S D=2.04)$. The main effect of meeting condition was not significant, $F(1,68)=2.34, p=.13, \eta^{2}=.03$, but there was an unexpected two-way interaction between depletion condition and meeting condition, $F(1,68)=4.08, p=.047, \eta^{2}$ $=.057$. To interpret this interaction, contrasts of the depletion versus non-depletion condition within the future meeting condition and within the no future meeting condition were tested. Within the future meeting condition, depleted participants $(M=6.55, S D=$ $0.66)$ reported exerting significantly more effort than non-depleted participants $(M=2.83$, $S D=1.37), F(1,68)=64.23, p<.001, \eta^{2}=.49$. A significant difference was also found between depleted $(M=6.38, S D=0.88)$ and non-depleted participants $(M=4.06, S D=$ 2.47 ) in the no future meeting condition, $F(1,68)=20.14, p<.001, \eta^{2}=.23$. Thus, the effect of the depletion manipulation was significant in both conditions, although the effect was unexpectedly larger in the future meeting condition. Insofar as the future interaction manipulation had not yet been administered when this measure was taken, the difference is presumably one of random fluctuation rather than any effect of that manipulation on perceived effort.

Trust Game-This experiment had a 2 (depletion versus non-depletion) $\times 2$ (future meeting $\mathrm{X}$ no future meeting) design. The primary prediction was that depleted participants would offer less money in the trust game to the other person than non-depleted participants — but primarily when they thought they would never meet the other person. A $2 \times 2$ ANOVA with depletion condition and meeting condition as independent variables was used to predict trust game offers. The only significant result was the predicted interaction between depletion condition and meeting condition, $F(1,68)=4.14, p=.046, \eta^{2}=.06$; see Figure 1.To interpret this interaction, we performed two contrasts comparing the effect of depletion condition within the no future meeting condition and within the future meeting condition. Consistent with the hypothesis, there was a significant effect of depletion condition among participants who did not expect to meet with the other person, $F(1,68)=$ 
$5.43, p=.02, \eta^{2}=.07$. Depleted participants in the no future meeting condition entrusted less money $(M=\$ 4.34, S D=\$ 2.39)$ to the other person than non-depleted participants $(M=$ $\$ 6.72, S D=\$ 3.17)$. This effect was not statistically significant in the future meeting condition, $F(1,68)=0.20, p=.65, \eta^{2}=.003$. Depleted participants $(M=\$ 6.14, M=\$ 3.05)$ and non-depleted participants $(M=\$ 5.72, S D=\$ 2.80)$ who expected to meet the other person made similar offer amounts.

Moderation Analyses-Experiment 1 provided preliminary evidence that the effect of depletion on trust game offer amounts was moderated by neuroticism scores as measured by the Big Five Aspects Scale. Regression analyses were run to test for replication of this effect in the current experiment. Depletion condition, neuroticism scores, and their centered interaction were entered as predictors of trust game offer amounts and meeting condition was entered as a covariate. The depletion condition by neuroticism interaction was in the same direction as in Experiment 1, but not significant, $\beta=-.11, p=.40, r_{\text {partial }}=-.10$. Similar results were also found when rerunning the regression equations replacing total neuroticism scores with scores from each of the two facets of the Big Five Aspects neuroticism scale, including Volatility, $\beta=-0.07, p=.59 r_{\text {partial }}=-.07$, and Withdrawal, $\beta=$ $-.15, p=.22, r_{\text {partial }}=-.15$.

Mood-Additional analyses were conducted to address the possibility that differences in mood valence or arousal can account for the observed effects. Depletion condition, meeting condition, and their interaction were entered in an ANOVA to predict mood valence or arousal. Mood valence did not differ by depletion condition, $p=.77$, meeting condition, $p$ $=.72$, or their interaction, $p=41$. Arousal also did not differ by depletion condition, $p=.70$, meeting condition, $p=.18$, or their interaction, $p=.59$. Additionally, we reran the primary analysis for trust game offer amounts controlling for mood valence and arousal. The interaction of depletion condition and meeting condition remained significant, $F(1,66)=$ $4.42, p=.04, \eta^{2}=.06$.

\section{Discussion}

Experiment 2 provided a conceptual replication of Experiment 1 and extended it by manipulating whether participants expected a future meeting with the other person. Replicating Experiment 1, we found lower levels of trust among depleted (than nondepleted) participants who expected no future meeting with their partner. That is, overriding some habitual responses while writing led people subsequently to entrust less money to another person. This effect was not statistically significant, however, among participants who expected a future interaction with the other person. That is, depleted and non-depleted participants were equally trusting of someone with whom they expected a future meeting. We theorized that trusting a stranger with whom you expect no meeting is more risky than trusting a person whom you plan to interact with in the future. When interacting anonymously with a stranger, intact self-regulatory resources may be especially important for enabling people to accept the potential risk in trusting others.

In Experiment 1, we found that the effect of depletion in reducing behavioral trust was specific to people who scored high on neuroticism. We tested for this effect in Experiment 2. 
Although the predicted interaction was in the same direction, it did not reach significance. This suggests that the neuroticism results of Experiment 1 should be interpreted with caution. This non-replication of the effect in Experiment 2 does not rule out the possibility that a real effect exists but instead suggests that additional tests of the hypothesis are needed before drawing conclusions. We therefore included the same measure of neuroticism in Experiment 3.

\section{Experiment 3}

In Experiment 3, participants again completed the trust game with an ostensible other person. In addition to the depletion manipulation, Experiment 3 also included a manipulation of apparent biological similarity between the participant and the other person. Participants underwent a fake EEG and were led to believe that another participant completed the same procedure at the same time. Participants either received no feedback about the results of the EEG reading or were told that the results indicated a high degree of similarity between them and the other person (Goldstein \& Cialdini, 2007; Maner et al., 2002). We predicted that depleted participants given no information about their partner would show decreased trust compared to non-depleted participants, replicating findings from Experiment 1 and Experiment 2 (no future meeting condition). Furthermore, we predicted that the effect of depletion on trust would be reduced among participants who were told the other participant was biologically similar to them. This prediction was based on the idea that the similarity manipulation may activate a default tendency to trust one's relatives.

\section{Method}

Participants-One-hundred thirty-one participants completed the experiment for partial course credit for the Introduction to Psychology courses. Participants received \$5 after completing the trust game, but they were unaware at the time they signed up for the experiment that they would receive this additional payment. Four participants who failed to answer the instruction check questions about the trust game correctly were excluded from analyses, leaving a total of 127 participants ( 82 women).

Procedure-Participants arrived individually at the laboratory for an apparent social neuroscience experiment on brain activity and personality. First, participants were led to believe that they would complete the experiment with another person. Both the participant and the other person would complete an electroencephalograph (EEG) reading that would supposedly allow researchers to assess their fundamental thinking styles and to meaningfully compare their results. After consenting to the EEG reading, all participants were asked to place a black headband around their head and then to insert three electrodes between the headband and their forehead. Although no physiological measures were actually recorded in this experiment, the electrodes used were borrowed from a machine capable of conducting electrocardiography, electromyography, and galvanic skin response measurements. After the electrodes were in place, the experimenter turned out the lights and started a slide show on the computer depicting words and images of objects taken from Google images. The words and images were all neutral in valence, such as the word 'banana'. Participants were instructed to allow their mind to freely associate while viewing the words and images. 
Following the fake EEG measurement period, participants completed the depletion manipulation described in detail in Experiment 2. Participants assigned to the depletion condition were instructed to answer three writing prompts without using the letters ' $\mathrm{A}$ ' and ' $\mathrm{N}$ ', and participants assigned to the non-depletion condition were instructed to answer the prompts without using the letters ' $\mathrm{X}$ ' and ' $\mathrm{Z}$ '. Following the depletion manipulation, participants were asked to indicate on a 7-point Likert-type scale how much effort, control, and overriding of typical responses the writing task demanded $(1=$ not at all, $7=$ very much). Participants' responses to these questions were averaged to provide a self-report check of the effectiveness of the depletion manipulation $(a=.95)$

Next, participants were randomly assigned to one of two similarity conditions. In the not similar condition, participants were told that the results of their EEG would be available later that week after they were analyzed by another lab. These participants were shown a copy of a sample individual EEG report, which depicted what looked like the output of an EEG reading. In the similar condition, participants were shown a copy of their individual report and an additional report indicating the degree of similarity between them and the other person. This report contained a similarity rating, and the experimenter explained that this rating conveys the similarity between the brainwave patterns of the participant and the other person as a percentage. The similarity rating for all participants in the similar condition was $93 \%$. Participants were further told that a rating of $93 \%$ conveys a substantial amount of similarity between two people, to the degree that would be expected to be found among siblings, identical twins, and close friends. Following the similarity manipulation, participants completed the Brief Mood Introspection Scale (BMIS; Mayer \&Gaschke, 1988) to provide a measure of mood and arousal.

Participants then completed the trust game. The instructions received were identical to the instructions from Experiment 2 with the exception that all participants were told they would not meet the other person at any time during or after the experiment. Decisions in the trust game, therefore, would remain confidential.

After the trust game, participants completed the Neuroticism subscale of the Big Five Aspects Scale ( $a=.87$; Volatility subscale $a=.85$, Withdrawal subscale $a=.77$ ) and the instruction check questions to confirm that participants understood the instructions of the trust game (see method from Experiment 1). Finally, participants were asked to rate on 7point Likert-type scales how likable the other person is, how similar they think they are to the other person, and how much they would use the term "WE" to characterize themselves and the other person $(1=$ not at all, $7=$ very much $)$. They were also asked to complete the Inclusion of Other in Self Scale (Aron, Aron, \& Smollan, 1992). This scale depicts a series of circles that become increasingly overlapping, and participants were asked to select the circle that best depicts how connected they felt to the other person. Participants' responses to these four questions were averaged to provide a self-report check of the effectiveness of the similarity manipulation $(a=.76)$.

\section{Results}

Manipulation check-A $2 \times 2$ ANOVA was run to test for differences in perceived effort on the writing task by depletion condition, similarity condition, and their interaction. There 
was a main effect of depletion condition, $F(1,123)=407.49, p<.001, \eta^{2}=.77$. Depleted participants $(M=6.33, S D=0.97)$ reported that the task was much more demanding than non-depleted controls $(M=2.69, S D=1.10)$. There was also an unexpected marginal main effect of similarity condition, $F(1,123)=3.57, p=.06, \eta^{2}=.03$. Participants in the similar condition $(M=5.32, S D=2.98)$ reported more exerting slightly more effort than participants in the not similar condition $(M=4.91, S D=2.64)$. The interaction was between depletion condition and similarity condition was not significant, $F(1,123)=2.32, p=.13$, $\eta^{2}=.02$. Although this interaction was not significant, we tested contrasts comparing the depletion versus non-depletion condition within the similar condition and within the not similar condition. Within the similar condition, depleted participants $(M=6.03, S D=1.18)$ reported exerting significantly more effort than non-depleted participants $(M=2.66, S D=$ $1.08), F(1,123)=178.20, p<.001, \eta^{2}=.60$. A significant difference was also found between depleted $(M=6.65, S D=0.55)$ and non-depleted participants $(M=2.72, S D=$ $1.34)$ in the not similar condition, $F(1,123)=230.31, p<.001, \eta^{2}=.65$. These results suggest that the depletion manipulation was effective.

A $2 \times 2$ ANOVA was run to test for differences in perceived similarity by depletion condition, similarity condition, and their interaction. There was a main effect of similarity condition, $F(1,123)=69.75, p<.001, \eta^{2}=.36$. Participants in the similar condition $(M=$ $6.07, S D=1.31)$ reported they perceived more similarity between themselves and the other person than participants in the not similar condition $(M=4.30, S D=1.06)$. This main effect was qualified by a significant interaction between depletion condition and similarity condition, $F(1,123)=5.12, p=.03, \eta^{2}=.04$. To interpret this interaction, contrasts of the depletion versus non-depletion condition within the similar condition and within the not similar condition were tested. Depleted participants in the similar condition $(M=6.34, S D=$ 1.22) reported feeling even more similar to the other person than non-depleted participants in the similar condition $(M=5.77, S D=1.36), F(1,123)=3.83, p=.05, \eta^{2}=.03$. Depleted $(M=4.12, S D=1.16)$ and non-depleted participants $(M=4.49, S D=0.92)$ in the not similar condition did not differ in their perception of partner similarity, $F(1,123)=1.57, p=.21, \eta^{2}$ $=.01$. These analyses indicate that the similarity manipulation effectively manipulated perceived similarity between the participant and the other person.

Trust Game-This experiment had a 2 (depletion versus non-depletion) $\times 2$ (similar versus not similar) design. The major prediction was that depleted participants would offer less money than non-depleted participants to the other person in the trust game, but that this effect would be attenuated for depleted participants in the similar condition. A $2 \times 2$ ANOVA indicated a marginal effect of depletion condition, $F(1,123)=2.97, p=.09, \eta^{2}=$. 02 . Depleted participants $(M=\$ 4.72, S D=\$ 2.79)$ offered marginally less money to the trustee than non-depleted participants $(M=\$ 5.55, S D=\$ 2.80)$. No main effect of similarity condition was observed, $F(1,123)=0.60, p=.44, \eta^{2}=.005$. The main effect of depletion condition was qualified by a significant interaction between depletion condition and similarity condition, $F(1,123)=3.97, p=.048, \eta^{2}=.03$. See Figure 2 . To interpret this interaction, we performed two contrasts comparing the effect of depletion condition within participants in the not similar condition and within participants in the similar condition. The effect of depletion condition among participants in the not similar condition was significant, 
$F(1,123)=6.75, p=.01, \eta^{2}=.05$. Depleted participants who were given no information about how similar they were to the other person $(M=\$ 4.02, S D=\$ 2.41)$ offered less money to the other person in the trust game than non-depleted participants given no information about the other person $(M=\$ 5.85, S D=\$ 2.57)$, thereby replicating the findings of Experiment 1. There was no difference in offer amounts between depleted $(M=\$ 5.38, S D=$ $\$ 2.99)$ and non-depleted $(M=\$ 5.25, S D=\$ 3.02)$ participants who were led to believe their brainwave patterns were similar to the other person's brainwave patterns, $F(1,123)=0.04, p$ $=.85, \eta^{2}<.001$.

Moderation Analyses-In Experiment 3, we again tested whether neuroticism scores moderated the relationship between depletion condition and trust game offers. Regression analyses were conducted with depletion condition, neuroticism, and their interaction as predictors of trust game offers with similarity condition as a covariate. The interaction between depletion condition and neuroticism was marginal, $\beta=-.16, p=.08, r_{\text {partial }}=.16$. Simple slopes analysis was conducted to interpret this interaction. We tested the effect of depletion condition at high (1 SD above the mean) and low (1 SD below the mean) levels of neuroticism. The effect of depletion condition was significant at high levels of neuroticism, $\beta=-0.31, p=.02, r_{\text {partial }}=-.22$, but not at low levels of neuroticism, $\beta=0.01, p=.92$, $r_{\text {partial }}=.01$. This indicates that depletion primarily decreased trust among participants who scored high on neuroticism.

Two additional regression analyses were run replacing the total neuroticism score with scores from each of the two facets of the Big Five Aspects Neuroticism Scale. Results indicate that the neuroticism interaction reported above was primarily driven by scores on the Volatility facet. Whereas the interaction between depletion condition and the Withdrawal facet was non-significant, $\beta=-.12, p=.21, r_{\text {partial }}=-.11$, the interaction between depletion condition and the Volatility facet was marginally significant, $\beta=-.16, p$ $=.08, r_{\text {partial }}=-.16$. Simple slopes analyses indicate the effect of depletion condition was significant at high levels of Volatility, $\beta=-0.31, p=.02, r_{\text {partial }}=-.22$, but not at low levels of Volatility, $\beta=0.01, p=.94, r_{\text {partial }}=.01$. Depletion decreased trust among participants who scored high on Volatility but not among participants who scored low on Volatility. This pattern of results replicates the findings from Experiment 1.

Mood-We conducted additional analyses to address the possibility that the results for the primary analysis of trust game offers were due to mood valence or arousal. Depletion condition, similarity condition, and their interaction were entered in an ANOVA to predict mood valence or arousal. Mood valence did not differ significantly by depletion condition, $p$ $=.37$, similarity condition, $p=.93$, or their interaction, $p=.41$. Mood arousal did not differ by depletion condition, $p=.94$ or the interaction of depletion condition and similarity condition, $p=.88$, but there was a marginal difference in mood arousal between participants in the similar condition and in the not similar condition, $F(1,123)=2.95, p=.09, \eta^{2}=.02$. Participants in the similar condition reported marginally higher mood arousal ( $M=14.40$, $S D=3.78)$ than participants in the not similar condition $(M=13.24, S D=3.73)$. To ensure that this trend cannot account for the results, we reran the primary analysis of trust game offer amounts controlling for mood valence and mood arousal. The depletion condition by 
similarity condition interaction remained significant, $F(1,121)=4.09, p=.045, \eta^{2}=.03$. Additionally, the interactions between depletion condition and neuroticism, $\beta=-.15, p=.09$, $r_{\text {partial }}=-.15$, and between depletion condition and Volatility, $\beta=-.16, p=.07, r_{\text {partial }}=-.17$, remained marginally significant when controlling for mood valence and arousal.

\section{Discussion}

Experiment 3 provided a replication of Experiments 1 and 2 and extended it by including a manipulation of the other person's similarity. Results indicated that depletion led to decreased trust, but primarily among participants who were given no information about the other person. The differences in behavioral trust between depleted and non-depleted participants were eliminated by telling participants that they had brainwave patterns similar to the trustee. We reasoned that leading participants to believe they might be genetically related to the other person may activate a default tendency to trust one's relatives.

In Experiment 1, depletion led to decreased trust among neurotic participants, but not among non-neurotic participants. In Experiment 2, the interaction between depletion condition and neuroticism was in the same direction but not significant. Experiment 3, however, again found that neuroticism scores moderated the effect of depletion on trust.

\section{General Discussion}

Three experiments found that self-regulatory depletion led to decreased behavioral trust in the trust game. Across three experiments, depletion reduced behavioral trust toward an anonymous other person. These findings complement those of Righetti and Finkenauer (2011), who showed that people with poor self-control are perceived to be relatively untrustworthy. The two sets of findings indicate that good self-control increases trust on both sides (i.e., both the truster and the trustee).

We also found that the relationship between self-control and trust was affected by relationship status between the truster and trustee. We had reasoned that the reluctance to trust others would vary as a function of relationship status, such that people trust more readily when a potential or actual relationship with the trustee exists. Consistent with that view, behavioral trust was high despite ego depletion among participants who had been led to expect a future meeting with the trustee (Experiment 2) or had been led to believe they were biologically similar to the trustee (Experiment 3 ). In other words, depletion decreased behavioral trust primarily among participants who did not expect to meet the trustee (Experiment 2) or who were not given any information about how similar they were to the trustee (Experiment 3).

\section{Implications of the Current Research}

The current research adds to a large body of evidence showing that self-control is used to override impulses that would otherwise lead to undesirable behavior (Vohs \& Baumeister, 2004). When self-control is depleted, people behave more dishonestly, provide less help to others, and become worse at restraining aggressive and the other personal urges (e.g., DeWall, Baumeister, Gailliot, \& Maner, 2008; DeWall, Baumeister, Stillman, \& Gailliot, 2007; Gailliot \& Baumeister, 2007; Mead, Baumeister, Gino, Schweitzer, \& Ariely, 2009), 
as compared to when their self-regulatory resources are intact. Our findings fit the view that self-control facilitates trust by allowing people to override tendencies to avoid social risk inherent in trusting behavior.

The current research also has implications for the formation of trust in virtual or economic transactions. Rational economic models predict minimal trust between strangers in the trust game, because the truster must assume that the trustee will keep all the money for himself or herself. Nonetheless, there is a robust literature showing that trusters often do choose to trust strangers (Berg, Dickhaut, \& McCabe, 1995; Lount, Zhong, Sivanathan, \& Murnighan, 2008; Yamagishi \& Yamagishi, 1994). Our findings showed that behavioral trust depended on self-control more when no actual or potential relationship existed between the participant and trustee. Self-regulation may be most important in establishing trust when very little social connection exists between truster and trustee, such as strangers interacting on websites such as eBay or Craigslist.

The current research also adds to evidence that many social behaviors are moderated by personality. Across three experiments, we measured neuroticism using the Big Five Aspects Neuroticism Scale. We found that neuroticism scores generally moderated the effect of depletion on behavioral trust. In Experiment 1 and 3, neuroticism scores moderated the effect of depletion on trust, such that depletion lowered trust mainly among neurotic participants. (Experiment 2 found the same pattern, but it was weaker and fell short of significance. Meta-analytic combination of findings across all three studies found the interaction to be significant.) The significant effects were driven by scores on the Volatility facet of the Big Five Aspects Neuroticism Scale, which is associated with attending to negative information, making negative attributions, and experiencing agitation or anger. These findings suggest that neurotics, and particularly those who score high on Volatility, may fail to trust because they are particularly sensitive to the potential negative consequences of trusting others. Neurotics, therefore, may depend more on self-regulation to trust others than non-neurotics.

\section{Limitations and Future Directions}

Limitations of the current research suggest directions for future research. The current research used a popular and valid measure of behavioral trust, but future research may benefit from using a different measure that would include inner feelings. We chose the trust game because this measure provides a tightly controlled laboratory measure of trust behavior. The one-round version of the trust game is also advantageous because it eliminates other possible explanations for trusting behavior, such as reciprocity norms. Indeed, in multiple round trust games, people may offer the other person money due to strategic selfinterest rather than trust if they are pursuing a tit-for-tat strategy (Kuhlman \& Marshello, 1975). Future research could profitably explore whether depletion decreases trust using other measures of trust and whether depletion decreases trust in non-economic domains.

Although the trust game has been used extensively, critics can suggest ambiguities. One issue is whether it is more about risk than about trust. Against that view, Houser, Schunk, and Winter (2010) found that general attitudes about risk failed to predict responses to the trust game. Thus, tolerance for risk does not appear to be the main factor. Another issue is 
whether allocation decisions are motivated more by altruistic concern for the other (i.e., wanting to make sure the other person gets some money) than by trust. This was tested by Cox (2004), who compared the standard trust game to a condition in which participants could allocate money to another person, which was then tripled but without any option of returning some of it. Allocations were substantially lower in the latter condition, which indicates the importance of trusting that the other person will in fact return some of the money. These other findings justify the assumption that the trust game really is about trust.

In the current research, we also focused specifically on behavioral trust between strangers. Self-control may play a less central role in facilitating trust among established relationship partners because (a) the behavior of the trustee should be more predictable, and (b) people may be motivated to trust an established friend, colleague, or romantic partner so as to build capital in their relationship. Indeed, results of Experiments 2 and 3 suggest that trust does not depend as heavily on self-control when there are situational or dispositional cues indicating that a relationship could develop (e.g., expecting a future meeting or viewing the trustee as similar to the self).

\section{Conclusion}

Three experiments demonstrated the role of self-control in facilitating trusting behavior. Whereas past research has shown that the self-control of the trustee affects perceptions of that person's trustworthiness (Righetti \& Finkenauer, 2011), the current research focused on the self-control of the truster. State fluctuations in the self-control of the truster affected decisions about whether to trust the partner, especially among highly neurotic people. The current experiments also provided evidence that self-control is most relevant in facilitating trust among strangers with whom no connection exists or is anticipated. Thus, self-control is relevant to interactions in the broader society that require trust.

\section{References}

Aron A, Aron EN, Smollan D. Inclusion of other in the self scale and the structure of interpersonal closeness. Journal of Personality and Social Psychology. 1992; 63:596612.10.1037/0022-3514.63.4.596

Balliet D, Van Lange PA. Trust, punishment, and cooperation across 18 societies: A meta-analysis. Perspectives on Psychological Science. 2013; 8:363-379.10.1037/a0023489

Baumeister RF, Bratslavsky E, Muraven M, Tice DM. Ego depletion: Is the active self a limited resource? Journal of Personality and Social Psychology. 1998; 74:12521265.10.1037/0022-3514.74.5.1252 [PubMed: 9599441]

Baumeister, RF.; Heatherton, TF.; Tice, DM. Losing control: How and why people fail at selfregulation. San Diego, CA: Academic Press; 1994.

Berg JE, Dickhaut JW, McCabe KA. Trust, reciprocity, and social history. Games and Economic Behavior. 1995; 10:122-142.10.1006/game.1995.1027

Brewer MB. In-group bias in the minimal intergroup situation: A cognitive-motivational analysis. Psychological Bulletin. 1979; 86:307-324.10.1037/0033-2909.86.2.307

Byrne D. Interpersonal attraction and attitude similarity. The Journal of Abnormal and Social Psychology. 1961; 62:713-715.10.1037/h0044721

Campbell L, Simpson JA, Boldry JG, Rubin H. Trust, variability in relationship evaluations, and relationship processes. Journal of personality and social psychology. 2010; 99:14-31.10.1037/ a0019714 [PubMed: 20565183] 
Cunningham WA, Abruckle NL, Jahn A, Mower SM, Abduljalil AM. Aspects of neuroticism and the amydala: Chronic tuning from motivational styles. Neuropsychologia. 2010; 48:33993404.10.1016/j.neuropsychologia.2010.06.026 [PubMed: 20600183]

Cox JC. How to identify trust and reciprocity. Games and Economic Behavior. 2004; 46:260 281.10.1016/S0899-8256(03)00119-2

Dawkins, R. The Selfish Gene. New York: Oxford University Press; 1976.

de Jong BA, Elfring T. How does trust affect the performance of ongoing teams? The mediating role of reflexivity, monitoring, and effort. Academy of Management Journal. 2010; 53:535549.10.5465/AMJ.2010.51468649

Delton AW, Krasnow MM, Cosmides L, Tooby J. Evolution of direct reciprocity under uncertainty can explain human generosity in one-shot encounters. Proceedings of the National Academy of Sciences. 2011; 108:13335-13340.10.1073/pnas.1102131108

DeWall CN, Baumeister RF, Gailliot MT, Maner JK. Depletion makes the heart grow less helpful: Helping as a function of self-regulatory energy and genetic relatedness. Personality and Social Psychology Bulletin. 2008; 34:1653-1662.10.1177/0146167208323981 [PubMed: 19050337]

DeWall CN, Baumeister RF, Mead NL, Vohs KD. How leaders self-regulate their task performance: Evidence that power promotes diligence, depletion, and disdain. Journal of Personality and Social Psychology. 2011; 100:47-65.10.1037/a0020932 [PubMed: 20919772]

DeWall CN, Baumeister RF, Stillman TF, Gailliot MT. Violence restrained: Effects of self-regulation and its depletion on aggression. Journal of Experimental Social Psychology. 2007; 43:6276.10.1016/j.jesp.2005.12.005

DeYoung CG, Quilty LC, Peterson JB. Between facets and domains: Ten aspects of the Big Five. Journal of Personality and Social Psychology. 2007; 93:880-896.10.1037/0022-3514.93.5.880 [PubMed: 17983306]

Dunning D, Fetchenhauer D, Schloesser T. Trust as a social and emotional act: Noneconomic considerations in trust behavior. Journal of Economic Psychology. 2012; 33:686-694.10.1016/ j.joep.2011.09.005

Evans AM, Revelle W. Survey and behavioral measurements of interpersonal trust. Journal of Research in Personality. 2008; 42:1585-1593.10.1016/j.jrp.2008.07.011

Fetchenhauer D, Dunning D. Do people trust too much or too little? Journal of Economic Psychology. 2009; 30:263-276.10.1016/j.joep.2008.04.006

Fetchenhauer D, Dunning D. Betrayal aversion versus principled trustfulness-How to explain risk avoidance and risky choices in trust games. Journal of Economic Behavior \& Organization. 2012; 81:534-541.10.1016/j.jebo.2011.07.017

Fukuyama, F. Trust: Human nature and the reconstitution of social order. Simon and Schuster; 1996.

Fukuyama, F. The origins of political order: From prehuman times to the French Revolution. Profile books; 2011.

Gilbert DT, Krull DS, Pelham BW. Of thoughts unspoken: Social inference and the self-regulation of behavior. Journal of Personality and Social Psychology. 1988; 55:685694.10.1037/0022-3514.55.5.685

Goldstein NJ, Cialdini RB. The spyglass self: A model of vicarious self-perception. Journal of Personality and Social Psychology. 2007; 92:402-417.10.1037/0022-3514.92.3.402 [PubMed: 17352600]

Hagger MS, Wood C, Stiff C, Chatzisarantis NL. Ego depletion and the strength model of self-control: a meta-analysis. Psychological Bulletin. 2010; 136:495-525.10.1037/a0019486 [PubMed: 20565167]

Hamilton WD. The evolution of social behavior. Journal of Theoretical Biology. 1964; 7:152.10.1016/0022-5193(64)90038-4 [PubMed: 5875341]

Holmes, JG.; Rempel, JK. Trust in close relationships. In: Hendrick, C., editor. Close relationships: Review of personality and social psychology. Thousand Oaks, CA: Sage Publications; 1989. p. 187-220.

Houser D, Schunk D, Winter J. Distinguishing trust from risk: An anatomy of the investment game. Journal of Economic Behavior and Organization. 2010; 74:82-81.10.1016/jebo.2010.01.002 
Kelley, HH.; Thibaut, JW. Interpersonal relations: A theory of interdependence. New York: Wiley; 1978.

Klapwijk A, Van Lange PA. Promoting cooperation and trust in "noisy" situations: the power of generosity. Journal of Personality and Social Psychology. 2009; 96:83-103.10.1037/a0012823 [PubMed: 19210066]

Knack S, Keefer P. Does social capital have an economic payoff? A cross-country investigation. The Quarterly journal of economics. 1997; 112:1251-1288.10.1162/003355300555475

Kuhlman DM, Marshello AF. Individual differences in game motivation as moderators of preprogrammed strategy effects in prisoners dilemma. Journal of Personality and Social Psychology. 1975; 32:922-931.10.1037/0022-3514.32.5.922 [PubMed: 1185519]

Lauriola M, Levin IP. Personality traits and risky decision making in a controlled experimental task: An exploratory study. Personality and Individual Differences. 2001; 31:215-226.10.1016/ S0191-8869(00)00130-6

Levin IP, Gaeth GJ, Schreiber J, Lauriola M. A new look at framing effects: Distribution of effect sizes, individual differences, and independence of types of effects. Organizational Behavior and Human Decision Processes. 2002; 88:411-429.10.1006/obhd.2001.2983

Lount RB, Zhong C, Sivanathan N, Murnighan JK. Getting off on the wrong foot: The timing of a breach and the restoration of trust. Personality and Social Psychology Bulletin. 2008; 34:16011612.10.1177/0146167208324512 [PubMed: 19050335]

Maner JK, Luce CL, Neuberg SL, Cialdini RB, Brown S, Sagarin BJ. The effects of perspective-taking on motivations for helping: Still no evidence for altruism. Personality and Social Psychology Bulletin. 2002; 28:1601-1610.10.1177/014616702237586

Masicampo EJ, Baumeister RF. Toward a physiology of dual-process reasoning and judgment. Psychological Science. 2008; 19:255-260.10.1111/j.1467-9280.2008.02077.x [PubMed: 18315798]

Mayer RC, Davis JH, Schoorman FD. An integrative model of organizational trust. Academy of management review. 1995; 20:709-734.10.5465/AMR.1995.9508080335

Mayer JD, Gaschke YN. The experience and meta-experience of mood. Journal of Personality and Social Psychology. 1988; 55:102-111.10.1037/0022-3514.55.1.102 [PubMed: 3418484]

McKnight DH, Cummings LL, Chervany NL. Initial trust formation in new organizational relationships. Academy of Management review. 1998; 23:473-490.10.5465/AMR.1998.926622

Mead NL, Baumeister RF, Gino F, Schweitzer ME, Ariely D. Too tired to tell the truth: Self-control resource depletion and dishonesty. Journal of Experimental Social Psychology. 2009; 45:594597.10.1016/j.jesp.2009.02.004 [PubMed: 20047023]

Newcomb TM. The prediction of interpersonal attraction. American Psychologist. 1956; 11:575586.10.1037/h0046141

Park JH, Schaller M. Does attitude similarity serve as a heuristic cue for kinship? Evidence of an implicit cognitive association. Evolution and Human Behavior. 2005; 26:158-170.10.1016/ j.evolhumbehav.2004.08.013

Pocheptsova A, Amir O, Dhar R, Baumeister RF. Deciding without resources: Resource depletion and choice in context. Journal of Marketing Research. 2009; 46:344-355.10.1509/jmkr.46.3.344

Rempel JK, Holmes JG, Zanna MP. Trust in close relationships. Journal of Personality and Social Psychology. 1985; 49:95-112.10.1037/0022-3514.49.1.95

Righetti F, Finkenauer C. If you are able to control yourself, I will trust you: The role of perceived self-control in interpersonal trust. Journal of Personality and Social Psychology. 2011; 100:874886.10.1037/a0021827 [PubMed: 21319912]

Rose, DC. The moral foundations of economic behavior. New York: Oxford University Press; 2011.

Rotter JB. Generalized expectancies for interpersonal trust. American Psychologist. 1971; 26:443452.10.1037/h0031464

Rousseau DM, Sitkin SB, Burt RS, Camerer C. Not so different after all: A cross-discipline view of trust. Academy of management review. 1998; 23:393-404.10.5465/AMR.1998.926617

Schmeichel BJ. Attention control, memory updating, and emotional regulation temporarily reduce the capacity for executive control. Journal of Experimental Psychology: General. 2007; 136:241255.10.1037/0096-3445.136.2.241 [PubMed: 17500649] 
Simpson JA. Psychological foundations of trust. Current Directions in Psychological Science. 2007; 16:264-268.10.1111/j.1467-8721.2007.00517.x

Tajfel, H.; Turner, JC. The social identity theory of intergroup behaviour. In: Worchel, S.; Austin, WG., editors. Psychology of Intergroup Relations. 2. Chicago: Nelson-Hall; 1986.

Van Doorn RAA, Lang JWB. Performance differences explained by the neuroticism facets withdrawal and volatility, variations in task demand, and effort allocation. Journal of Research in Personality. 2010; 44:446-452.10.1016/j.jrp.2010.05.004

Vohs, KD.; Baumeister, RF. Ego depletion, self-control, and choice. In: Vohs, KD.; Baumeister, RF., editors. Handbook of Experimental Existential Psychology. New York: Guilford Press; 2004. p. 398-410.

Vohs KD, Baumeister RF, Ciarocco NJ. Self-regulation and self-presentation: regulatory resource depletion impairs impression management and effortful self-presentation depletes regulatory resources. Journal of Personality and Social Psychology. 2005; 88:636657.10.1037/0022-3514.88.4.632

Yamagishi T, Yamagishi M. Trust and commitment in the United States and Japan. Motivation and Emotion. 1994; 18:129-166.10.1007/BF02249397

Zaheer A, McEvily B, Perrone V. Does trust matter? Exploring the effects of interorganizational and interpersonal trust on performance. Organization Science. 1998; 9:141-159.10.1287/orsc.9.2.141 


\section{Highlights}

- We provide evidence that ego depletion reduced behavioral trust in economic decision making.

- Depletion decreased trust only when participants did not anticipate interacting with the trustee (Experiment 2) or did not perceive the trustee as similar to themselves (Experiment 3).

- The current findings imply that self-control facilitates trust, particularly in the absence of cues that signal decreased social risk in trusting others. 


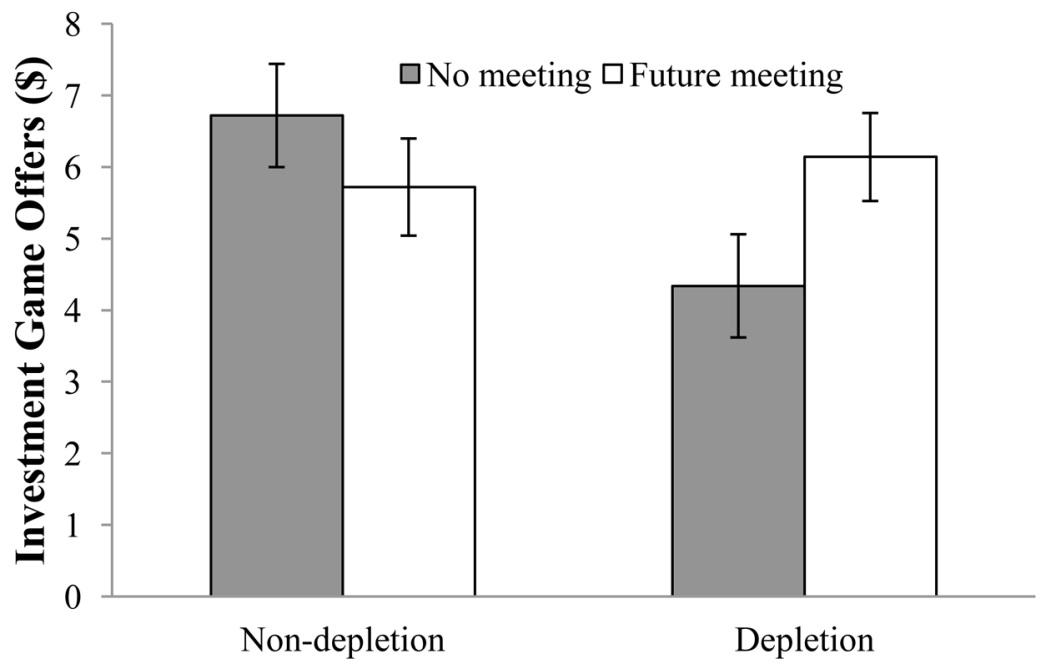

Figure 1.

Depleted participants in Experiment 2 offered less money than non-depleted participants in the trust game, but primarily when they did not expect to meet the trustee. 


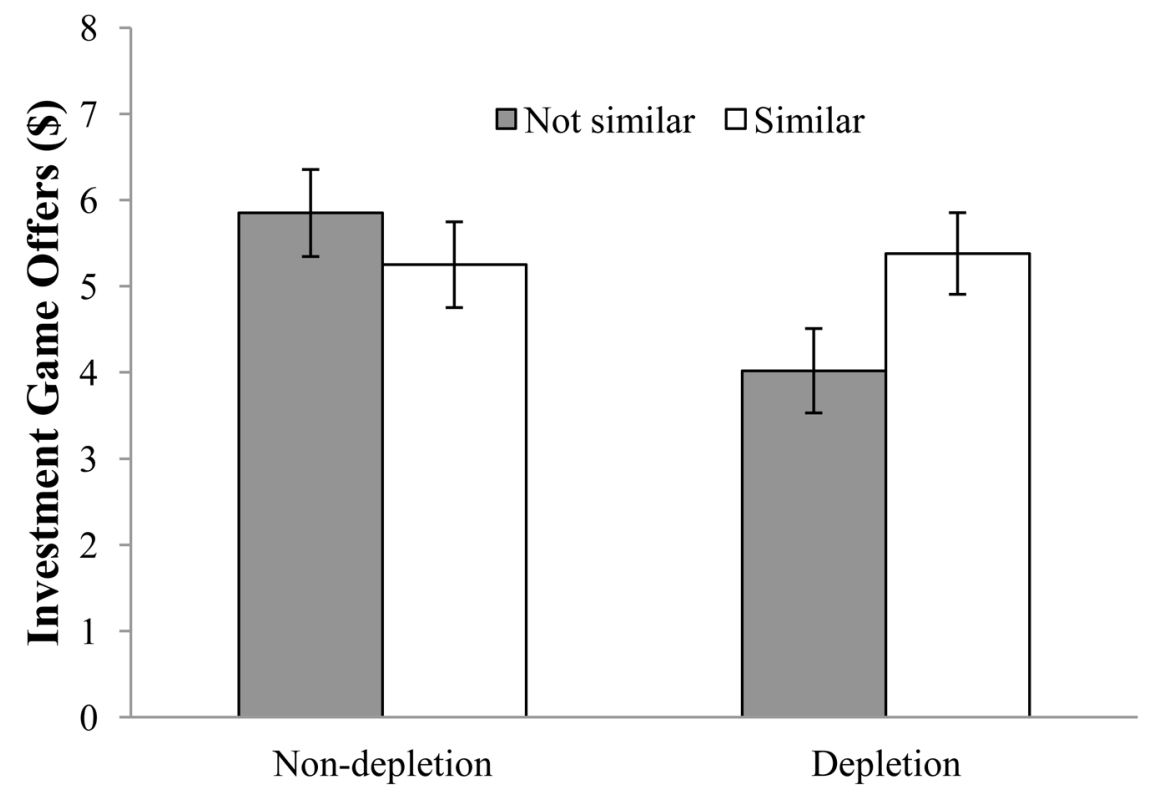

Figure 2.

Depleted participants in Experiment 3 offered less money than non-depleted participants in the trust game, but primarily when they received feedback indicating they share a high degree of similarity with the trustee. 